\title{
MANAGING CULTURE COMPONENTS IN INTERNATIONAL BUSINESS
}

\author{
${ }^{*}$ Cynthia Menezes, PhD
}

\begin{abstract}
International business necessitates businesses to be conversant with the culture of different countries. This can be achieved through cross-cultural training. As part of the UGC funded project "Cross-cultural training as an entry strategy- An empirical study of a few selected Multinational Corporations of Bangalore City", this paper analyses the components of culture that are at play as either blatantly open or unseen, important forces that determine the culture that affects international business.
\end{abstract}

\section{Introduction}

Growing numbers of Indian companies are coming to realize that the ability of their employees to communicate and interact more effectively is an important competitive factor. Foreign companies in India are showing more keenness to develop the business and leader- ship skills of their Indian employees and to move gradually from the cheap labour or staff augmentation model to one where the Indian operation is a value-adding centre of excellence. According to a recent report from Bangalore, local cultural awareness program providers are often entrepreneurs with a background in the hospitality industry. The content of such cultural training will tend to be weighted towards form more than substance 19 more concerned with handshakes, business cards, dining etiquette and accent neutralization than the deeper core value differences that affect business culture and work relationships. (Schomer, 2006)

\section{Culture}

Culture is the combination of all the physical and behavioral aspects of a society. Culture is process to live in group. Each society has norms to follow by individuals in order to retain society strong and intact. Culture is a process for identity of living creatures and cultural evolution raises the identity of society, benefit goes to its individuals. Culture differentiates from group to group (as behavior changes) though major part remains same as human culture to differentiate from other species.(Sadashivan). Culture is an integral part of every society. It is a learned pattern of behavior and ways in which a person lives his or her life. Culture is essential for the existence of a society, because it binds people together. In the explicit sense of the term, culture constitutes the music, food, arts and literature of a society. However, these are only the products of cufture followed by the society and cannot be defined Fas éulture. According to English Anthropologist Eatard B Taylor, culture is that complex whole which includes knowledge, belief, art, law, morals, custom, and any other capabilities and habits acquired by man as a member of society.

Culture is something that a person learns from his family and surroundings, and is not ingrained in him from birth. It does not have any biological connection because even if a person is brought up in a culture different from that in which he was born, he imbibes the culture of the society where he grows up. It is also not a hidden fact that some people feel the need to follow the beliefs and traditions of their own culture, even though they might be not subscribing to certain ideologies within. Culture is a complex tool which every individual has to learn to survive in a society. It is the means through which people interact with others in the society. It acts in a subconscious way and whatever we see and perceive, seems to be normal and natural. Sometimes, other societies and people seem to be a little odd because they have a different culture from ours.

\footnotetext{
${ }^{*}$ Reader, MBA Department, Bangalore University
} 
Culture does not remain stagnant, on the other hand it is evolving constantly and is in fact somewhat influenced by the other cultures and societies. Every society has a different culture, where people share a specific language, traditions, behaviors, perceptions and beliefs. Culture gives them an identity which makes them unique and different from people of other cultures. When people of different cultures migrate and settle in another society, the culture of that society becomes the dominant culture and those of the immigrants form the subculture of the community. Usually, people who settle in other nations imbibe the new culture, while at the same time strive to preserve their own. Although every society has a specific culture, there are certain elements of culture that are universal. They are known as cultural universals, in which there are certain behavioral traits and patterns that are shared by all cultures around the world. For instance, classifying relations based on blood relations and marriage, differentiating between good and bad, having some form of art, use of jewellery, classifying people according to gender and age, etc., are common in all cultures of the world. Culture is necessary to establish an order and discipline in the society. It is not only a means of communication between people, but also creates a feeling of belonging and togetherness among people in the society.(Deepa)

\section{Types of culture}

Basically, organizational culture is the personality of the organization. Culture is comprised of the assumptions, values, norms and tangible signs (artifacts) of organization members and their behaviors. Members of an organization soon come to sense the particular culture of an organization. Culture is one of those terms that's difficult to express distinctly, but everyone knows it when they sense it. For example, the culture of a large, forprofit corporation is quite different than that of a hospital which is quite different than that of a university.

Corporate culture can be looked at as a system. Inputs include feedback from, e.g., society, professions, laws, stories, heroes, values on competition or service, etc. The process is based on our assumptions, values and norms, e.g., our values on money, time, facilities, space and people. Outputs or effects of our culture are, e.g., organizational behaviors, technologies, strategies, image, products, services, appearance, etc. The concept of culture is particularly important when attempting to manage organization-wide change. Practitioners are coming to realize that, despite the best-laid plans, organizational change must include not only changing structures and processes, but also changing the corporate culture as well. There are different types of culture just like there are different types of personality. Researcher Jeffrey Sonnenfeld identified the following four types of cultures.

Academy Culture: Employees are highly skilled and tend to stay in the organization, while working their way up the ranks. The organization provides a stable environment in which employees can development and exercise their skills. Examples are universities,

up ohospitals, large corporations, etc.

\#asếball Team Culture: Employees are "free agents" Whave highly prized skills. They are in high demand and can rather easily get jobs elsewhere. This type of culture exists in fast-paced, high-risk organizations, such as investment banking, advertising, etc.

o 2011

Club Culture: The most important requirement for employees in this culture is to fit into the group. Usually employees start at the bottom and stay with the organization. The organization promotes from within and highly values seniority. Examples are the military, some law firms, etc.

Fortress Culture: Employees don't know if they'll be laid off or not. These organizations often undergo massive reorganization. There are many opportunities for those with timely, specialized skills. Examples are savings and loans, large car companies, etc. (McNamara)

Organizational culture has brought about a radical change in the functioning of different organizations. It is basically the study of organizational management and studies, which includes the description of attitude, psychology, belief, 
experience, personal and cultural values of an organization. Like varied personalities, there are different types of organizational cultures that function, by following a method of working, that is best suited to their core business. Following are the main types of organization structures found today, on which types of culture can be based:

Normative Culture: In a normative organization, the organization stresses on implementing the organizational procedures in a correct way, and according to the norms and rules defined. This kind of culture is perceived to portray, a high standard of business ethics.

Pragmatic Culture: In contrast to normative cultures, stress is laid on satisfying the wish of their clients. In this type of organizational structure, no norms are set by the company, and utmost importance is given to the needs of the client.

Tough-Guy Culture or Macho Culture: The most important aspect of this kind of culture is big rewards and quick feedback. This kind of culture is mostly associated with quick financial activities like brokerage and currency trading. It can also be related with activities, like a sports team or branding of an athlete, and also the police team. This kind of culture is considered to carry along, a high amount of stress, and people working within the organization are expected to possess a strong mentality, for survival in the organization.

Work Hard/Play Hard: This type of organization does not involve much risk, as the organizations already consist of a firm base along with a strong client relationship. This kind of culture is mostly opted by large organizations which have strong customer service. The organization with this kind of culture is equipped with specialized jargons and is qualified with multiple team meetings.

Bet Your Company Culture: In this kind of culture, the company makes big and important decisions over high stakes endeavors. It takes time to see the consequence of these decisions. Companies that postulate experimental projects and researches as their core business, adopt this kind of culture. This kind of culture can be adopted by a company designing experimental military weapons for example.

Process Culture: This type of culture does not include the process of feedback. In this kind of culture, the organization is extremely cautious about the adherence to laws and prefers to abide by them. This culture provides consistency to the organization and is good for public services.

\section{Components of culture}

The three components of culture include language, customs, and land. These components are found in every-day life. The most interesting fact about culture is that everyone has a culture of their own. Daily activities, monthly celebrations, and annual remembrances constitute the major component of culture known as customs. Customs are activities and events that occur on regular basis.

The next component of culture is language. Language is the sounds and written symbols that allowy people to express their thoughts, their feelings, GaLfheir hopes, and their dreams with themselves and $\wedge$ with one another. Language is the one unifying component of culture that binds one member of a Ogroupl to another. In fact, language can be said to be a major cornerstone of culture. Without language, people cannot interact; without interaction, there is no identity with the group.

The component of land in the discussion of culture is often missed by sociologists and anthropologists alike. This component is the real bedrock of culture (pun intended). There is no thriving culture without land. If a people lose their land, they become a surviving culture or an extinct culture. History is full of groups of people who have lost their land and then vanished-the Babylonians, the Assyrians, and the Carthaginians. Land is a major component of culture. Culture, then, is that ephemeral quality consisting of customs, language, and land. In other words, these three components equal culture. (Papadopoulos) 


\section{Communication}

To interact, people need to communicate. Communication exchanges information, ideas, feelings, etc. using language and symbols as the medium, the carrier. Language and symbols give people shared set of gestures and vocalizations they use to express what they mean (how they're interpreting stimuli), see/hear other's interpretations, and adjust behavior accordingly.

Symbols: Along with language and non-verbal signals, symbols form the backbone of symbolic interaction. They condense very complex ideas and values into simple material forms so that the very presence of the symbol evokes the signified ideas and values. Not only is this more efficient than verbal or written language but it also skips over possible disagreements and nuances created by talking about these values and ideas using language. Sociology uses the word "symbols" in two ways. (1) A general capacity of the human species ("symbolic interaction"). (2) Specific objects or behaviors used during symbolic interaction.

Corporate brands can be symbolic, e.g., Coke, Cadillac and Disney. Most college classes start with a "syllabus," a symbolic document. Clothing can take on symbolic meaning (baseball hats worn sideways, belly shirts).

Cognitive component: People can interact when they share the "same world." Rather than passively reflecting the world, human minds construct "worlds" by slicing up and organizing the flow of stimulus coming in through the senses. Different "realities" result when different ideas, assumptions, etc. slice and organize stimulus into different forms. People in different cultures live in different worlds.

Ideas / Knowledge / Beliefs: Ideas are mental representations (concepts, categories, metaphors) used to organize stimulus; they are the basic units out of which knowledge is constructed and a world emerges. When linked together and organized into larger sets, systems, etc., ideas become knowledge. Knowledge systematically summarizes and elaborates how we think the world looks and acts. Knowledge is the storehouse where we accumulate representations, information, facts, assumptions, etc. Once stored, knowledge can support learning and can be passed down from one generation to the next. Beliefs accept a proposition, statement, description of fact, etc. as "true." Acceptance uses criteria found in knowledge systems provided by an external authorities (science, religion, government, etc.), rather than from personal, direct experience. Explanations and predictions (cause and effect logic) rely on beliefs. People sharing a culture use a common set of ideas and knowledge to slice and dice stimuli in and separate true from false facts. Knowledge and belief systems can range from abstract and theoretical to concrete and practical. Our society has three general knowledge/belief systems: Science, Religion and political ideology.

Values: Values are criteria for evaluating ourselves, others, and the world in general. Values classify things as good/evil, beautiful/ugly, or sacred/ordinary.

up orlyalues and symbols often co-exist in the world. Physical presence of the symbol means physical existence of the value. That explains why symbols carry such emotional baggage and why attacking or VAL improperly using a symbol can evoke such a strong emotional, even violent, response.

Accounts: People who share a culture share a common language for talking about their inner selves. Accounts are how people use that common language to explain, justify, rationalize, excuse, or legitimize our behavior to themselves and others.

Motives: are verbalizations that lay out the "why" of our behavior. Usually we think of motives as hidden springs of action that create behavior, but culturally they are linguistic devices created after behavior happens.

Norms: are shared expectations about what is considered normal, socially-acceptable behavior. They distinguish "normative" from "deviant." Norms organize interaction. When people follow norms, behavior is predictable and interaction falls into predictable patterns. Interaction is efficient, smooth, and engaged in with little conscious thought. Norms can generate, regulate and prohibit. 
Generate - Create the behavior, interaction, and social situation The social situation exists only so long as people follow the rules and the situation comes into existence when people follow the rules.

Regulate - Create boundaries or parameters around behavior Norms create a corridor defining the acceptable limits of variation, creativity, and innovation. Within the corridor people need to use their creative skills to fine tune and adjust behavior to meet the immediate needs of the situation.

Prohibit - Prevent behavior: While tempting to compare norms to rules of a game, the comparison misleads more than enlightens. Most often norms only provide guidelines, models, or broad outlines for what is considered "normative." To be socially competent, people must interpret how norms apply in the context of specific situations.

Laws: Explicit system of norms enforced by formal social control (police, courts, prisons)

Folkways: Rules of conventional behavior, everyday customs, and good manners. Examples: wearing socks with dress pants, eating with a fork.

Rituals: Rituals are highly scripted strips of interaction that follow a specific sequence of actions. Occur at predetermined times or triggered by specific cues.

Ceremonies: graduation, baptism, funerals,, 9 weddings, Bar Mitzvah, birthdays.

Holidays: Thanksgiving, Christmas, Hanukah, 4th of July

Every day public rituals: Handshake, greeting, walking on the right side of the sidewalk, birthday wrappings and cards.

Bonding rituals: exchanging business cards, holding hands, parties, gift giving, flirting, holding hands, watching football games.

Signal rituals: Closing the menu in the restaurant when want to order, eye contact, holding the door. Many symbols are activated only during ritual ceremonies and many rituals have symbols as their central orientation. Rituals reinforce the solidarity of culture, its "sharedness" feeling, by individuals participating in predictable behavior and experiencing the same world at the same time.
Material Component: Material culture can range from the sacred/sublime to the everyday/ordinary; from the symbolic to the practical. Examples of Material Culture: Technology / Tools, Computers, Internet.

Implications of culture on international business: When the two aspects of human society, culture and business, interact with each other, it leads to the development of interesting conditions or scenarios. When different cultures converge at a common point with business as the platform, the clashes are bound to take place. But most importantly, such a scenario helps us adapt to challenging situations. Different communities or countries in the world follow different mannerisms and etiquette. The way or view to see a problem might change from country to country, across the globe. The international business culture, as a whole, is a congregation of various business practices, cultural influences and the thought processes followed in different nations. Understanding a foreign up ormarket and formulating the company policies to cater to the need of international clients is a challenging Job. Skilled professionals possessing the quality called 'empathy' are able to deliver the goods in such GaL cases. With today's businesses entering a ' globalized ' world, the interaction between different cultures is bound to happen. Merely learning different Olanguages, won't be enough. It is necessary for corporate houses to understand the social conditions of different countries, to successfully tap the respective markets. Being sensitive to the values and beliefs of different cultures of the world is necessary. (Nakate) Understanding and appreciating intercultural differences ultimately promotes clearer communication, breaks down barriers, builds trust, strengthens relationships, opens horizons and yields tangible results in terms of business success. When organisations become cross-border entities, cross-cultural factors start affecting every aspect of the business. Whether in multi-cultural teams or in business interactions, the variants of cultural nuances eventually end up affecting the business. Misinterpretations and misconceptions are to be expected when the identical situation is viewed contrarily by people from different cultures. The basis of inter-cultural relations 
are not around altering other people, but adapting oneself to another culture. Misinterpretations due to cultural factors can be detrimental to a company's business. The need is for superior empathy and adaptability.

Cross cultural training is an important element in the development of individual and organisational competence, which underpins the social cohesion and social capital of....society. Social cohesion and the development of human capital rely to a large degree on a society's social capital, described as the networks and norms of reciprocity and trust that enhance productivity (McGaw, 2006). Underpinning social capital and social cohesion is cultural competence, which can be broadly described as the ability of systems, organisations, professions and individuals to work effectively in culturally diverse environments and situations. Cross-cultural training, which aims to develop the awareness, knowledge and skills needed to interact appropriately and effectively with culturally diverse customers and co-workers, is an important element in the development of cultural competence. Cultural competence is critical to the achievement of national multicultural policy objectives. Cultural competence is vital to international trade performance and the fulfilment of international diplomacy and security responsibilities. The recognition and leveraging of workforce cultural diversity can also constitute a sustainable competitive advantage for enterprises in every industry. (Bean, 2006).

\section{References}

1. Dr. Karine Schomer, Improving the CrossCultural Competency of Offshore Teams. Viewed on CMCT website.

2. Jennifer L. Aaker and Durairaj Maheswaran, The Effect of Cultural Orientation on Persuasion, Research Paper No. 1635, Journal of Consumer Research, No. 24, No. 3 (Dec., 1997), pp. 315-328. Viewed on SSRN website.

3. John Barkai, Cultural dimension interests, the dance of negotiation, and weather forecasting: A perspective on cross-cultural negotiation and dispute resolution. Viewed on SSRN website.
4. Meena S. Wilson AND Jeffrey Yip, Grounding Leader Development: Cultural Perspectives, Industrial and Organizational Psychology, 3 (2010), 52-55. Viewed on SSRN website.

5. Robert Bean, Cultural Diversity Services Pty $L t d$, The Effectiveness of Cross-Cultural Training in the Australian Context, November 2006.

6. Jenny Castelino, Director Global Performance Solutions, Asia Pacific, "The Importance of Cross-Cultural Training for Intra-Regional Moves in Asia Pacific", McKinsey Quarterly, 2006 Special Edition

7.http://www.sadashivan.com/ freephotos4ursocialstudy/id23.html

8. Deepa, http://www.buzzle.com/articles/ * what-is-culture.html

Nakate Shashank, http://www.buzzle.com/ articles/culture-impacts-on-an-internationalbusiness.html
VE A 10. Carter McNamara, MBA, PhD. Published by Authenticity Consulting, LLC, 2000. Adapted from the Field Guide to Leadership and Supervision. http://managementhelp.org/ org_thry/culture/culture.htm

11. Palmira S, http://www.buzzle.com/articles/ types-of-organizational-culture.html

12. Payne, Neil, http://www.sideroad.com/ Cross Cultural Communication/crosscultural-training.html

13. Dean Papadopoulos, PhD, Northern Marianas College, Saipan. 